\title{
Reduced repair of 8-hydroxyguanine in the human breast cancer cell line, HCCI 937
}

\author{
Simon G Nyaga ${ }^{1}$, Althaf Lohani ${ }^{1}$, Pawel Jaruga ${ }^{2,3}$, Andrzej R Trzeciak ${ }^{1}$, \\ Miral Dizdaroglu ${ }^{4}$ and Michele K Evans*1
}

\begin{abstract}
Address: ${ }^{1}$ Laboratory of Cellular and Molecular Biology, National Institute on Aging, National Institutes of Health, Baltimore, MD 21224, USA, ${ }^{2}$ Department of Chemical and Biochemical Engineering, University of Maryland Baltimore County, Baltimore, MD 21250, USA, ${ }^{3}$ Department of Clinical Biochemistry, Collegium Medicum, Nicolaus Copernicus University, Bydgoszcz, Poland and ${ }^{4}$ Chemical Science and Technology Laboratory, National Institute of Standards and Technology, Gaithersburg, MD 20899, USA

Email: Simon G Nyaga - nyagas@grc.nia.nih.gov; Althaf Lohani - lohania@grc.nia.nih.gov; Pawel Jaruga - pawel.jaruga@nist.gov; Andrzej R Trzeciak - trzeciakan@grc.nia.nih.gov; Miral Dizdaroglu - miral.dizdar@nist.gov; Michele K Evans* - me42v@nih.gov

* Corresponding author
\end{abstract}

Published: 27 December 2006

BMC Cancer 2006, 6:297 doi:10.1186/147|-2407-6-297
Received: 20 October 2006

Accepted: 27 December 2006

This article is available from: http://www.biomedcentral.com//47/-2407/6/297

(C) 2006 Nyaga et al; licensee BioMed Central Ltd.

This is an Open Access article distributed under the terms of the Creative Commons Attribution License (http://creativecommons.org/licenses/by/2.0), which permits unrestricted use, distribution, and reproduction in any medium, provided the original work is properly cited.

\begin{abstract}
Background: Breast cancer is the second leading cause of cancer deaths in women in the United States. Although the causes of this disease are incompletely understood, oxidative DNA damage is presumed to play a critical role in breast carcinogenesis. A common oxidatively induced DNA lesion is 8-hydroxyguanine (8-OH-Gua), which has been implicated in carcinogenesis. The aim of this study was to investigate the ability of HCCI 937 and MCF-7 breast cancer cell lines to repair 8-OH-Gua relative to a nonmalignant human mammary epithelial cell line, AG I I 34.
\end{abstract}

Methods: We used oligonucleotide incision assay to analyze the ability of the two breast cancer cell lines to incise $8-\mathrm{OH}$-Gua relative to the control cell line. Liquid chromatography/mass spectrometry (LC/MS) was used to measure the levels of 8-OH-Gua as its nucleoside, $8-\mathrm{OH}-\mathrm{dG}$ in the cell lines after exposure to $\mathrm{H}_{2} \mathrm{O}_{2}$ followed by 30 min repair period. Protein expression levels were determined by Western blot analysis, while the hOGGI mRNA levels were analyzed by RTPCR. Complementation of hOGGI activity in HCCI937 cells was assessed by addition of the purified protein in the incision assay, and in vivo by transfection of pFlagCMV-4-hOGGI. Clonogenic survival assay was used to determine sensitivity after $\mathrm{H}_{2} \mathrm{O}_{2}$-mediated oxidative stress.

Results: We show that the $\mathrm{HCCl} 937$ breast cancer cells have diminished ability to incise 8-OHGua and they accumulate higher levels of 8-OH-dG in the nuclear genome after $\mathrm{H}_{2} \mathrm{O}_{2}$ treatment despite a 30 min repair period when compared to the nonmalignant mammary cells. The defective incision of 8-OH-Gua was consistent with expression of undetectable amounts of hOGGI in $\mathrm{HCCl} 937$ cells. The reduced incision activity was significantly stimulated by addition of purified hOGGI. Furthermore, transfection of pFlagCMV-4-hOGGI in HCCI 937 cells resulted in enhanced incision of 8-OH-Gua. $\mathrm{HCCl} 937$ cells are more sensitive to high levels of $\mathrm{H}_{2} \mathrm{O}_{2}$ and have upregulated SODI and SOD2.

Conclusion: This study provides evidence for inefficient repair of 8-OH-Gua in $\mathrm{HCCl} 937$ breast cancer cell line and directly implicates hOGGI in this defect. 


\section{Background}

Aerobic organisms are constantly exposed to endogenous and exogenous reactive oxygen species (ROS). Endogenous ROS include hydroxyl radicals that are produced predominantly as byproducts of normal cellular metabolism and through leakage of electrons during the mitochondrial electron transport chain. The interaction of ROS with the cellular genome often results in oxidatively induced DNA damage that includes; DNA base and sugar modifications, DNA-protein cross-links, abasic sites, single-strand breaks (SSB) and double-strand breaks (DSB) [1].

One of the most common oxidatively induced DNA base modifications is 8-hydroxyguanine (8-OH-Gua), which mispairs with adenine during DNA replication causing $\mathrm{GC} \rightarrow$ TA transversion mutations [2,3]. To maintain proper genetic integrity and to minimize cancer risk, organisms ranging from $E$. coli to humans have evolved elaborate mechanisms for repairing 8-OH-Gua [4]. The MutT, MutM, and MutY pathways provide efficient repair of 8OH-Gua in E. coli [5]. MutT and its human homologue $\mathrm{hMTH}$ is an $8-\mathrm{OH}$-dGTpase that cleanses the nucleotide pool of 8-OH-GuaTP thus preventing its incorporation into the DNA during DNA replication. MutY and its human homolog hMYH is a monofunctional DNA glycosylase that removes adenine opposite 8-OH-Gua. MutM (Fpg) is a DNA glycosylase/AP lyase that specifically removes 8-OH-Gua opposite cytosine. In humans, 8-OHGua is repaired predominantly by hOGG1, a DNA glycosylase/AP lyase that is specific for 8-OH-Gua and 2,6diamino-4-hydroxy-5-formamidopyrimidine (FapyGua) opposite cytosine [6-9] via the base excision repair (BER) pathway $[10,11]$.

A few studies have associated oxidatively induced DNA damage with cancer, [reviewed in [12]]. These include studies by Malins et al., showing increased hydroxyl radical-induced DNA damage in DNA of invasive ductal breast carcinoma tissues relative to normal breast tissue $[13,14]$. Olinski et al., showed that free radical-induced DNA damage is elevated in chromatin of various surgically removed malignant tissues from the colon, stomach, ovary, brain and lung relative to the surrounding nonmalignant tissues [15]. In addition, peripheral blood lymphocytes of women at high risk of developing breast cancer have been shown to be deficient in the repair of Xirradiation-induced DNA damage [16]. Furthermore our laboratory recently showed that mitochondrial extracts but not nuclear extracts of breast cancer cell lines, MCF-7 and MDA-MB-468 are defective in the repair of 8-OH-Gua [17], consistent with increased levels of ROS in the mitochondria produced during the electron transport. It has also been shown that cell free extracts of HCC1937 cell line are defective in transcription-coupled repair (TCR) of
8-OH-Gua [18]. Here, we show that HCC1937 breast cancer cells are deficient in the repair of 8-OH-Gua when compared to nonmalignant mammary epithelial cells. We further show that HCC1937 breast cancer cells express undetectable levels of hOGG1. In addition, these cells accumulate elevated levels of 8-OH-Gua after $\mathrm{H}_{2} \mathrm{O}_{2}$ challenge despite a cellular repair period at $37^{\circ} \mathrm{C}$. The repair of 8-OH-Gua was stimulated by addition of purified hOGG1 in vitro and in vivo by transient expression of hOGG1 in HCC1937 cells. This study directly implicates hOGG1 in the defective repair of 8-OH-Gua in HCC1937 breast cancer cells.

\section{Methods}

\section{Cell lines and culture conditions}

HCC1937 is a primary ductal breast carcinoma cell line that was purchased from American Type Culture Collection (ATCC Manassas, VA). The HCC1937 cells were cultured in RPMI 1640 media containing 10 mM HEPES, 1 $\mathrm{mM}$ sodium pyruvate, $2 \mathrm{mM}$ L-glutamate, $4500 \mathrm{mg}$ glucose/L, $1500 \mathrm{mg}$ sodium bicarbonate supplemented with $10 \%$ FBS. MCF-7 is an epithelial breast adenocarcinoma cell line that was purchased from ATCC (Manassas, VA). MCF-7 cells were cultured in Minimum Essential Medium supplemented with $10 \%$ FBS, $1 \mathrm{mM}$ sodium pyruvate, 2 $\mathrm{mM}$ L-glutamine, and $1500 \mathrm{mg}$ sodium bicarbonate. The AG11134 is a nonmalignant human mammary epithelial cell line that was obtained from the Aging Cell Repository (Coriell Institute for Medical Research, Camden, NJ). The AG11134 cell line was cultured in serum-free mammary epithelial growth media (Cambrex, Walkersville, MD) supplemented with bovine pituitary extracts, human epidermal growth factor, insulin and hydrocortisone, gentamycin and amphotericin-B according to the supplier's instructions. All the cells had normal morphology and were harvested at viability greater than $95 \%$.

\section{Preparation of nuclear extracts}

Approximately $1.0 \times 10^{8}$ cells were harvested and pelleted by centrifugation at $585 \times g$ at $4{ }^{\circ} \mathrm{C}$ for 5 min using a tabletop centrifuge (Beckman Coulter, Allegra, 6R). The cell pellet was washed twice with PBS by centrifugation at 585 $\times g$ for $5 \mathrm{~min}$ at $4{ }^{\circ} \mathrm{C}$ and the supernatant was saved for use in mitochondrial extract preparation. The cell pellet was lysed by homogenization (35 strokes) using a glass-glass dounce homogenizer (Thomas Scientific, Swedesboro, $\mathrm{NJ}$ ) in buffer A (10 mM HEPES, pH 7.4; $0.21 \mathrm{M}$ mannitol; $0.07 \mathrm{M}$ sucrose; $0.15 \mathrm{M}$ spermine; $0.75 \mathrm{M}$ spermidine; 1 mM EDTA; $0.5 \mathrm{mM}$ DTT) and protease inhibitors in the indicated final concentrations; $1 \mathrm{mM}$ phenylmethylsulfonylfluoride (PMSF); $2 \mu \mathrm{M}$ benzamide; $1 \mu \mathrm{g} / \mathrm{mL}$ chymostatinA; $1 \mu \mathrm{g} / \mathrm{mL}$ pepstatinA; $1 \mu \mathrm{g} / \mathrm{mL}$ aprotinin; $2 \mu \mathrm{g} / \mathrm{mL}$ leupeptin and $1 \mu \mathrm{M}$ E64. The homogenate was spun at $500 \times g$ for 7 min at $4{ }^{\circ} \mathrm{C}$ (Beckman, Avanti J-25I) and the nuclear pellet was sonicated (Ultrasonic Processor GE130, 
Sonics \& Materials, Inc., Newtown, CT) 3- times for $5 \mathrm{~s}$ each in half volume of buffer B (20 mM HEPES, pH 7.9; 25\% glycerol; $0.2 \mathrm{mM}$ EDTA; $0.5 \mathrm{mM}$ DTT and $0.2 \mathrm{mM}$ PMSF) on ice. The sonicated pellet was incubated on ice for $30 \mathrm{~min}$ before centrifugation for $30 \mathrm{~min}$ at 25,000 $\times \mathrm{g}$ at $4{ }^{\circ} \mathrm{C}$ (ultracentrifuge, Beckman XL-90). The supernatant was aliquoted and stored in $-80^{\circ} \mathrm{C}$. Total protein amounts were assessed by the Bradford assay (Bio-Rad, Hercules, CA).

\section{Preparation of whole cell and mitochondrial extracts}

Whole cell extracts were prepared using approximately 1.0 $\times 10^{8}$ cells as previously described [19]. Mitochondrial extracts were prepared from $1.0 \times 10^{8}$ cells following the procedure described earlier [20]. The nonmalignant cell line, AG10097 was used as a control for mitochondrial incision assay since it was difficult to grow enough of the primary AG11134 cells to prepare mitochondrial extracts for incision assay. The protein concentrations were assessed by the Bradford assay (Bio-Rad, Hercules, CA).

\section{Measurement of 8-OH-Gua in hydrogen peroxide-treated cells}

Cells were grown in $150 \times 25 \mathrm{~mm}$ tissue culture dishes in the respective media up to $85 \%$ confluency. The cells were washed twice with $1 \times \mathrm{PBS}$ and treated with $300 \mu \mathrm{M} \mathrm{H}_{2} \mathrm{O}_{2}$ (Sigma-Aldrich, ST. Louis, MO) in $10 \mathrm{~mL}$ of $1 \times$ PBS. The control cells were treated with $10 \mathrm{~mL}$ of $1 \times$ PBS. The cells were incubated at $37^{\circ} \mathrm{C}, 5 \% \mathrm{CO}_{2}$ and $95 \%$ relative humidity for $30 \mathrm{~min}$. After this incubation, the $\mathrm{H}_{2} \mathrm{O}_{2}$ was removed and the cells were washed twice with $1 \times$ PBS. After this wash, $25 \mathrm{~mL}$ of media were added to the dishes and the cells incubated at $37^{\circ} \mathrm{C}$ for a further $30 \mathrm{~min}$. After the $30 \mathrm{~min}$ incubation, the media was removed and the cells washed twice with $1 \times$ PBS. The cells were loosened by scrapping lightly and genomic DNAs were isolated by the salt extraction method [21]. The DNA samples were hydrolyzed to nucleosides using a mixture of three enzymes [22]. The hydrolysates were analyzed by liquid chromatography/mass spectrometry with isotope-dilution to quantitatively measure $8-\mathrm{OH}-\mathrm{Gua}$ as its nucleoside 8-hydroxy-2' -deoxyguanosine (8-OH-dG) using 8-OH$\mathrm{dG}^{-15} \mathrm{~N}_{5}$ as an internal standard as described [22].

\section{End-labeling of oligonucleotide}

The 8-OH-Gua- or uracil-containing oligonucleotides had the following sequences:

\section{5'-ATACGCATATACCGCT8-OH-GuaTCGGCCGATCTC- CGAT-3', 5'-ATATACCGCGGUCGGCCGATCAAGCT- TATT-3'. The positions of 8-OH-Gua and uracil (U) are shown in bold font. Approximately, $100 \mathrm{ng}$ of the single- stranded oligonucleotides were 5' end-labeled with 30 $\mu \mathrm{Ci}$ of $[\gamma-32 \mathrm{P}]$ ATP $(3,000 \mathrm{Ci} / \mathrm{mmoL})$ using T4 polynucle- otide kinase and annealed to 4-fold excess complemen-}

tary oligonucleotides. The reactions were heated at $90^{\circ} \mathrm{C}$ for $10 \mathrm{~min}$ and then slow cooled to room temperature. The duplex oligonucleotides contained cytosine opposite 8-OH-Gua and guanine opposite uracil. Electrophoresis of the sample aliquots through $20 \%$ native polyacrylamide gel confirmed complete conversion of labeled single-stranded oligonucleotides to labeled duplex oligonucleotides.

\section{8-OH-Gua incision assay}

The $5^{\prime}$ end-labeled duplex oligonucleotides were incubated with nuclear extracts at $37^{\circ} \mathrm{C}$ and the incision products analyzed qualitatively and quantitatively. The reactions were performed in buffer containing $20 \mathrm{mM}$ HEPES, pH7.4, 5\% glycerol, $0.1 \mathrm{mM} \mathrm{NaCl}, 5 \mathrm{mM}$ EDTA, $5 \mathrm{mM}$ DTT, $100 \mu \mathrm{g} / \mathrm{mL}$ BSA, and $25 \mu \mathrm{g} / \mathrm{mL}$ poly $(\mathrm{dI})$ poly $(\mathrm{dC})$. The hOGG1 reactions in the complementation of activity assay were performed following the procedure provided by the supplier of hOGG1 (Trevigen Inc., Gaithersburg, MD). All reactions were stopped by incubation with $0.2 \%$ SDS and $0.1 \mathrm{mg} / \mathrm{mL}$ proteinase $\mathrm{K}$ at $60^{\circ} \mathrm{C}$ for $15 \mathrm{~min}$. The DNA was purified using phenol/ chloroform/isoamylalcohol and the products separated by electrophoresis through $20 \%$ polyacrylamide gels containing $7 \mathrm{M}$ urea at $15 \mathrm{~W}$ for $80 \mathrm{~min}$. The gels were exposed in PhosphorImager cassettes and the gel images analyzed using PhosphorImager and ImageQuant version 5.1 (Amersham Biosciences, Piscataway, NJ). The product bands were quantified appropriately relative to the sum of the substrate and product bands and expressed as a percentage.

\section{Western blot analysis}

The nuclear or whole cell extracts were mixed with sample loading buffer and then denatured by heating at $95^{\circ} \mathrm{C}$ for $10 \mathrm{~min}$. The samples were loaded on a $6 \%$ or $12 \%$ Trisglycine gels (Invitrogen, Carlsbad, CA) and separated by electrophoresis in 1X Tris-glycine SDS buffer. The proteins were subsequently transferred to PVDF membranes (Invitrogen, Carlsbad, CA). The membranes were blocked for $1 \mathrm{~h}$ in 5\% dry milk in PBS-Tween (0.2\%) and then probed with the following primary antibodies: OGG1 (Novus Biologicals, Littleton, CO), APE1 (Novus Biologicals), NEIL1 (Oncogene, San Diego, CA), p53 (Oncogene, San Diego, CA), SOD1 (Calbiochem, San Diego, CA), SOD2 (Abcam, Cambridge, MA) and catalase (Calbiochem). The membranes were washed and incubated with horseradish peroxidase-conjugated secondary antibodies and then developed using enhanced chemiluminescence plus Western detection kit (Amersham Biosciences, Piscataway, NJ). Loading errors were controlled using antibody against $\beta$ actin (Santa Cruz Biotechnology, Santa Cruz, CA). 


\section{Stimulation of 8-OH-Gua specific activity in HCCI937 cells}

Increasing amounts of hOGG1 were incubated at $37^{\circ} \mathrm{C}$ with approximately $20 \mathrm{ng}$ of a duplex $5^{\prime}$ end-labeled oligonucleotide containing a single $8-\mathrm{OH}-\mathrm{Gua}$ and $50 \mu \mathrm{g}$ of nuclear extracts from HCC1937 in a $20 \mu \mathrm{l}$ reaction. The reactions were heated to $90^{\circ} \mathrm{C}$ for $10 \mathrm{~min}$ and then $20 \mu \mathrm{l}$ of oligonucleotide loading buffer containing 95\% formamide, 5\% glycerol and $0.02 \%$ bromophenol blue and $0.02 \%$ xylene cyanol was added. The samples were then separated by electrophoresis through $20 \%$ polyacrylamide gels containing $7 \mathrm{M}$ urea. The band images were captured on phosphorImager cassettes and then analyzed by Imagequant software (PhorsphorImager).

\section{RNA isolation and RT- PCR}

Total RNA was isolated from approximately $8.0 \times 10^{6}$ cells by the single-step method using TRIzol reagent (Invitrogen, Carlsbad, CA) according to the manufacturer's instructions. Briefly, $1 \mu \mathrm{g}$ of total RNA was reverse-transcribed using 100 units MMLV RT (RETROscript kit, Ambion, Inc, Austin, TX) in a total volume of $20 \mu \mathrm{L}$. The hOGG1 cDNA was amplified for 22 cycles by PCR using the following primers: forward, 5'CCTACACCTCAGGAAAGCC 3' and reverse, 5' GGGAAGATAAAACCATCCTTAG 3'. $\beta$-actin was amplified for 30 cycles using commercial primers (Clontech Laboratories, Inc., Palo Alto, CA) and was used as a loading control. The amplification conditions used for both hOGG1 and $\beta$-actin cDNAs had been determined to be within the linear range of the product formation and also for detection on gels.

\section{Transient transfection of pFlag-CMV-4 with or without hOGGI gene}

HCC1937 cells $\left(1.0 \times 10^{6}\right)$ were plated in several $100 \mathrm{~mm}$ $\times 20 \mathrm{~mm}$ tissue culture dishes in the relevant media without antibiotics and incubated at $37^{\circ} \mathrm{C}$. After $24 \mathrm{~h}$ the cells were washed with $1 \times$ PBS and transfected with pFlagCMV-4 plasmid carrying hOGG1 1a gene using DMRIE-C reagent (Invitrogen) according to the supplier's instructions. Nuclear and whole cell extracts were prepared thereafter. The expression of hOGG1 protein was examined by Western blot analysis using whole cell extracts and the incision activity was assayed using the nuclear extracts following the incision assay described above.

\section{Clonogenic survival}

$1.0 \times 10^{6}$ cells (AG11134, MCF-7 and HCC1937) were plated in triplicate in $100 \mathrm{~mm} \times 20 \mathrm{~mm}$ dishes in their respective media and incubated at $37^{\circ} \mathrm{C}$ in the presence of $5 \% \mathrm{CO}_{2}$. After $24 \mathrm{~h}$, the cells were washed twice with $1 \times$ PBS and treated with $0,50,150$ and $300 \mu \mathrm{M}$ of $\mathrm{H}_{2} \mathrm{O}_{2}$ in PBS for $30 \mathrm{~min}$. The cells were then washed twice with $1 \times$ PBS and incubated at $37^{\circ} \mathrm{C}, 5 \% \mathrm{CO}_{2}$ for $2 \mathrm{~h}$ in their respective media. The cells were then trypsinized and 2.5 $\times 10^{4}$ cells were serially diluted. The diluted cells were replated in $100 \mathrm{~mm} \times 20 \mathrm{~mm}$ dishes and incubated at $37^{\circ} \mathrm{C}$ for 20 days. The surviving colonies were quantified using MCID computer software.

\section{Statistical Analysis}

Statistical analysis was performed using Statistica 6.1 (Statsoft Inc. Tulsa, OK). Data are presented as arithmetic means with error bars representing standard error of mean (SEM) calculated from at least three independent experiments. All statistical tests and corresponding $p$-values were two-sided. Differences between means were tested for significance using the student's t-test applying one- or twoway ANOVA. Where necessary post-hoc tests were performed by multiple comparisons between the experimental means relative to the control mean. A $p$ value $<0.05$ was regarded as statistically significant.

\section{Results}

8-OH-Gua is poorly incised by $\mathrm{HCCl} 937$ nuclear extracts We tested the ability of nuclear extracts prepared from the breast cancer cell lines to incise an oligonucleotide containing 8-OH-Gua relative to the nonmalignant mammary epithelial cell line AG11134. HCC1937 nuclear extracts exhibited a statistically significant $(p<0.0002)$ diminished ability to incise an 8-OH-Gua-containing oligonucleotide compared to the nonmalignant mammary epithelial cell line, AG11134 (compare Fig. 1B with 1A, $1 \mathrm{C}$ and $1 \mathrm{D}$, triangles with circles and squares). Nuclear extracts from MCF-7 incised 8-OH-Gua-containing oligonucleotide more effectively than the HCC1937 and the AG11134 cell lines. Fpg, a well-characterized DNA glycosylase/AP lyase incised the 8-OH-Gua-containing oligonucleotide yielding a product that had similar mobility with the products of incision by the extracts (Fig. 1A-C). These results suggest the presence of endonucleolytic activity of APE in the extracts. The incision of uracil by nuclear extracts from the two breast cancer cell lines, HCC1937 and MCF-7, was qualitatively and statistically similar to that of the nonmalignant mammary epithelial cell line, AG11134 (Fig. 2A-D). Thus, these results show that the breast cancer cell line HCC1937 is deficient in the incision of 8-OH-Gua. We noted that MCF-7 cells incised 8-OH-Gua relatively well probably due to the presence of detectable hOGG1 in the nuclear extracts of this cell line (Fig. 4A). A 13-mer band appeared in MCF-7 reactions (Fig. 2C). This band appears to be a nonspecific product since it did not change in the time course experiment.

\section{Measurement of 8-OH-Gua levels in genomic DNA}

In order to test the hypothesis that the breast cancer cell lines may be overwhelmed by oxidatively induced DNA damage after exposure to oxidative stress, we used LC/MS with isotope-dilution to measure the levels of 8-OH-Gua as its nucleoside $8-\mathrm{OH}-\mathrm{dG}$ in the genomic DNA of 

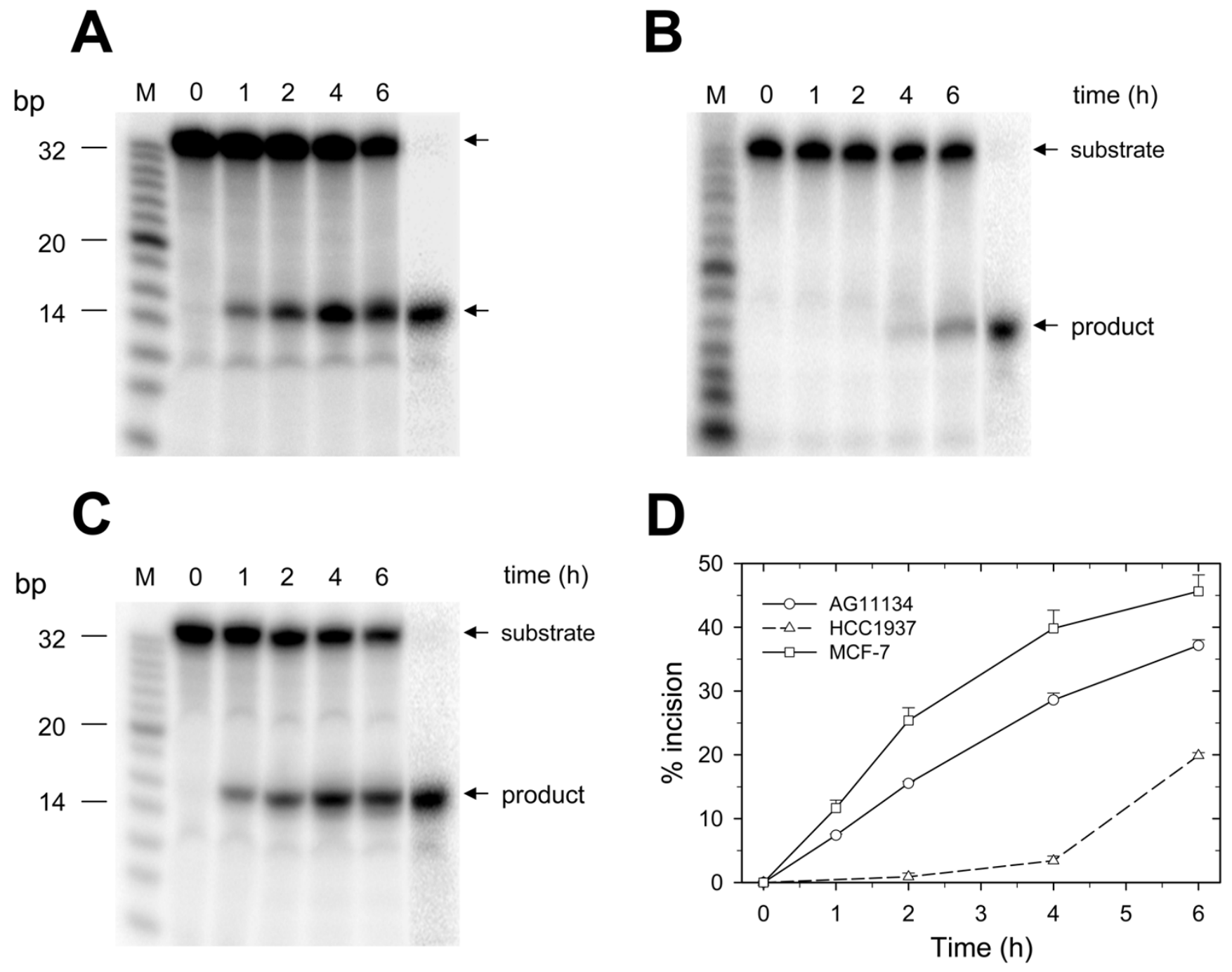

\section{Figure I}

Incision of 8-OH-Gua by AG I I 34 and HCCI 937 nuclear extracts. 5' end-labeled duplex oligonucleotides containing single $8-\mathrm{OH}$-Gua were incubated at $37^{\circ} \mathrm{C}$ with $50 \mu \mathrm{g}$ of nuclear extracts and aliquots removed at specified intervals as shown in the figure. The Fpg reactions were performed for $30 \mathrm{~min}$. The reactions were stopped by the addition of $0.25 \%$ SDS and heating at $90^{\circ} \mathrm{C}$ for $10 \mathrm{~min}$. The DNAs were purified by phenol/chloroform/isoamyl alcohol extraction method and then separated by electrophoresis through $20 \%$ denaturing gels. The Panels are: A, $8-\mathrm{OH}-\mathrm{Gua}$ incision by AG I II 34 nuclear extracts; B, 8-OH-Gua incision by HCCI 937 nuclear extracts; $\mathbf{C}$, 8-OH-Gua incision by MCF-7 nuclear extracts and $\mathbf{D}$, quantified incision of 8-OH-Gua by AG I I 34, MCF-7 and HCCI 937 nuclear extracts. The results are representative of three independent experiments and the error bars represent SEM.

HCC1937, MCF-7 and AG11134 cells. The chemical structure of $8-\mathrm{OH}-\mathrm{dG}$ is shown in Fig. 3A. This analysis revealed that there was a statistically significant increase in the levels of 8-OH-dG in genomic DNA of HCC1937 and MCF-7 cells after exposure to $300 \mu \mathrm{M}$ of $\mathrm{H}_{2} \mathrm{O}_{2}$ despite a 30 min repair period at $37^{\circ} \mathrm{C}$ (compare Fig. $3 \mathrm{~B}$, solid bars with open bars). There were no statistically significant differences between the levels of the 8-OH-dG in DNA of untreated AG11134 cells relative to $\mathrm{H}_{2} \mathrm{O}_{2}$-treated AG11134 cells (Fig. 3B), indicating complete repair of 8-
$\mathrm{OH}$-dG in this cell line. In contrast, $\mathrm{H}_{2} \mathrm{O}_{2}$-treated breast cancer cell lines accumulated significantly greater levels of 8-OH-dG, suggesting that the in vivo repair of 8-OH-Gua was deficient in the breast cancer cell lines, HCC1937 and MCF-7.

\section{Expression of DNA repair proteins and hOGGI I a mRNA}

To examine whether the reduced incision of the 8-OHGua-containing oligonucleotide is associated with the levels of hOGG1 and other proteins that influence DNA 


\section{A}
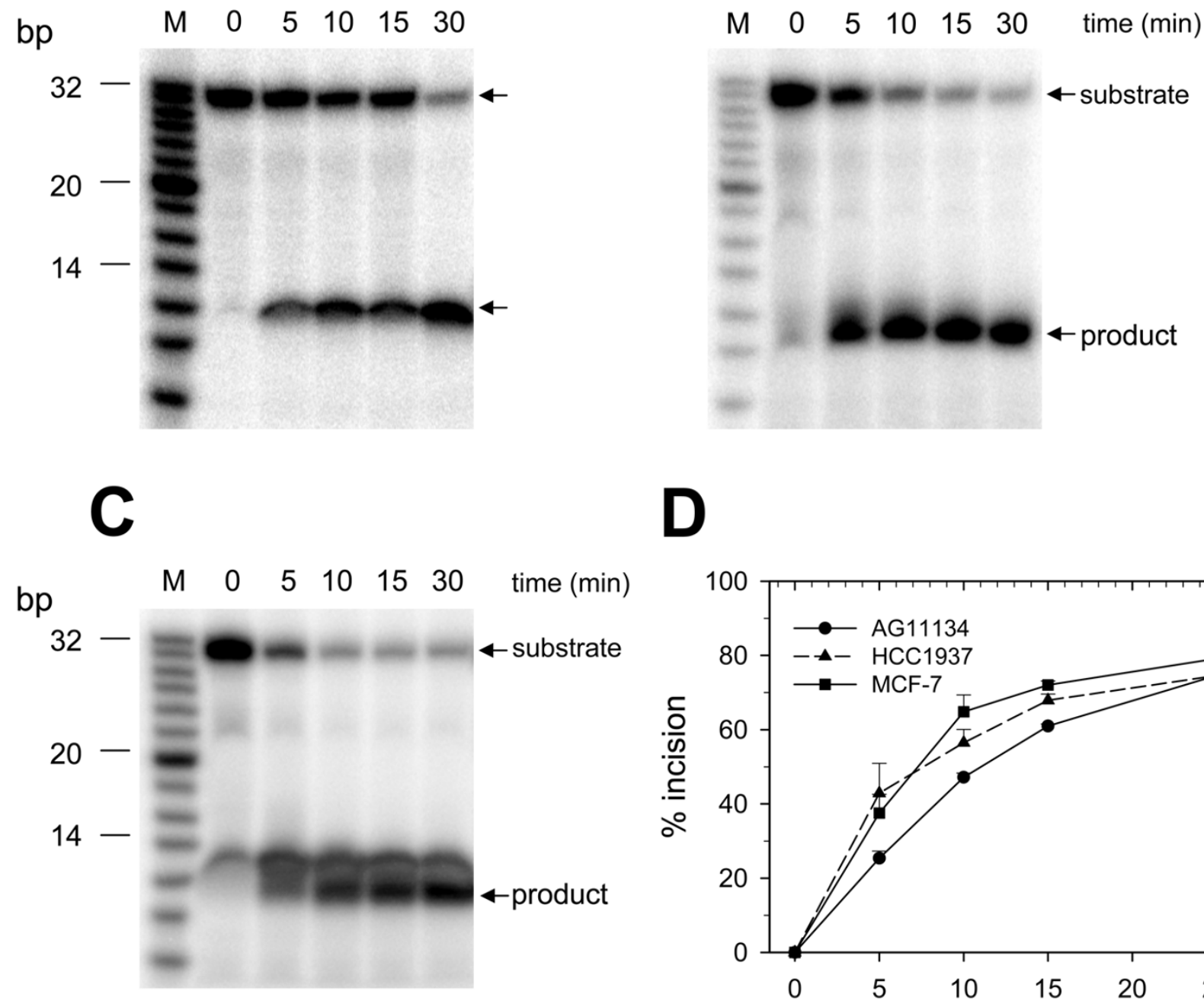

B
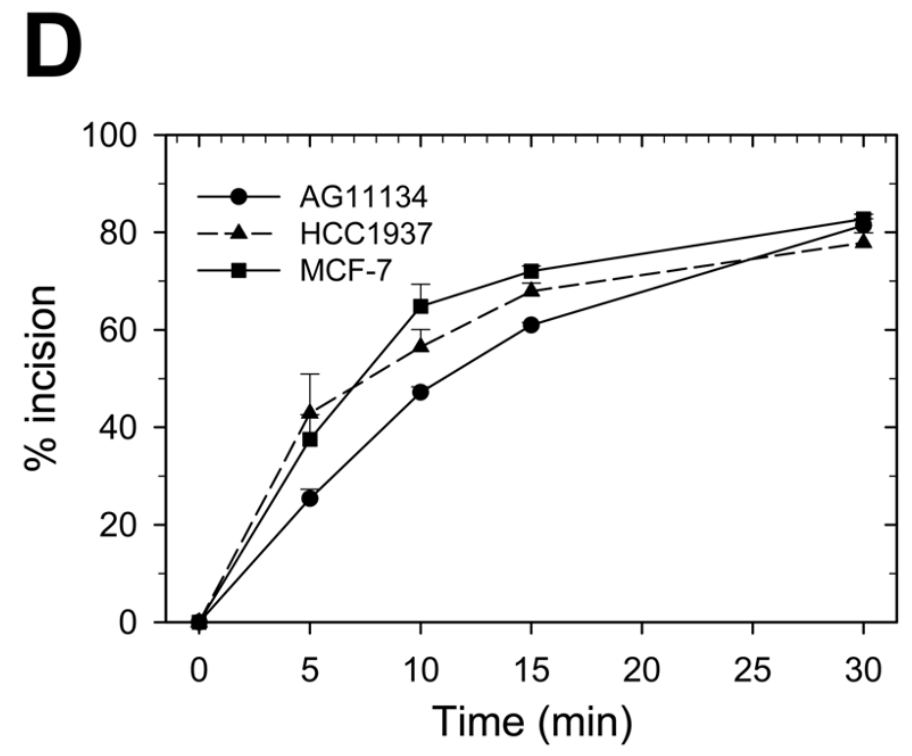

Figure 2

Incision of uracil by AG I I I 34 nuclear extracts. The experiment was performed as in Fig. I except that uracil-containing oligonucleotide was used instead of 8-OH-Gua-containing oligonucleotide. Panel $\mathbf{A}$, incision of uracil by AG I I I 34 nuclear extracts, $\mathbf{B}$, incision of uracil by $\mathrm{HCC} 1937$ nuclear extracts, $\mathbf{C}$, incision of uracil by MCF-7 nuclear extracts and D, quantified incision of uracil by AGI I I34, HCCI937 and MCF-7 nuclear extracts. The results represent three independent experiments.

repair activity, we analyzed the expression of hOGG1, APE1, NEIL1 and p53 proteins in HCC1937 and MCF-7 relative to the control AG11134 cells. Western blot analysis showed that HCC1937 nuclear extracts had an undetectable level of hOGG1, while MCF-7 nuclear extracts did express active hOGG1 although at a slightly lower level than the control AG11134 nuclear extracts (Fig. 4A). APE1 was significantly upregulated in both HCC1937 and MCF7 cells compared to AG11134 cells, whereas NEIL1 was over-expressed in MCF-7, but expressed at wild type level in HCC1937 cells. The p53 protein was undetectable in
HCC1937 nuclear extracts but significantly overexpressed in MCF-7 nuclear extracts (Fig. 4A). These results suggest that the inefficient incision of $8-\mathrm{OH}-\mathrm{Gua}$ in HCC1937 cells could be due to undetectable levels of the hOGG1 in HCC1937.

In order to determine whether the reduced expression level of hOGG1 in the two breast cancer cell lines correlated with transcriptional regulation, we examined the expression of hOGG1 1a mRNA by RT-PCR. The results show that OGG1 1a gene was effectively transcribed in 


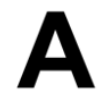<smiles>NC1=Nc2c3nc(O)n2[C@@H](O[C@H](O)CO)C(=N1)NC3=O</smiles>

\section{8-hydroxy-2'-deoxyguanosine}

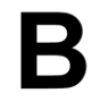

\section{AG11134 HCC1937 MCF-7}

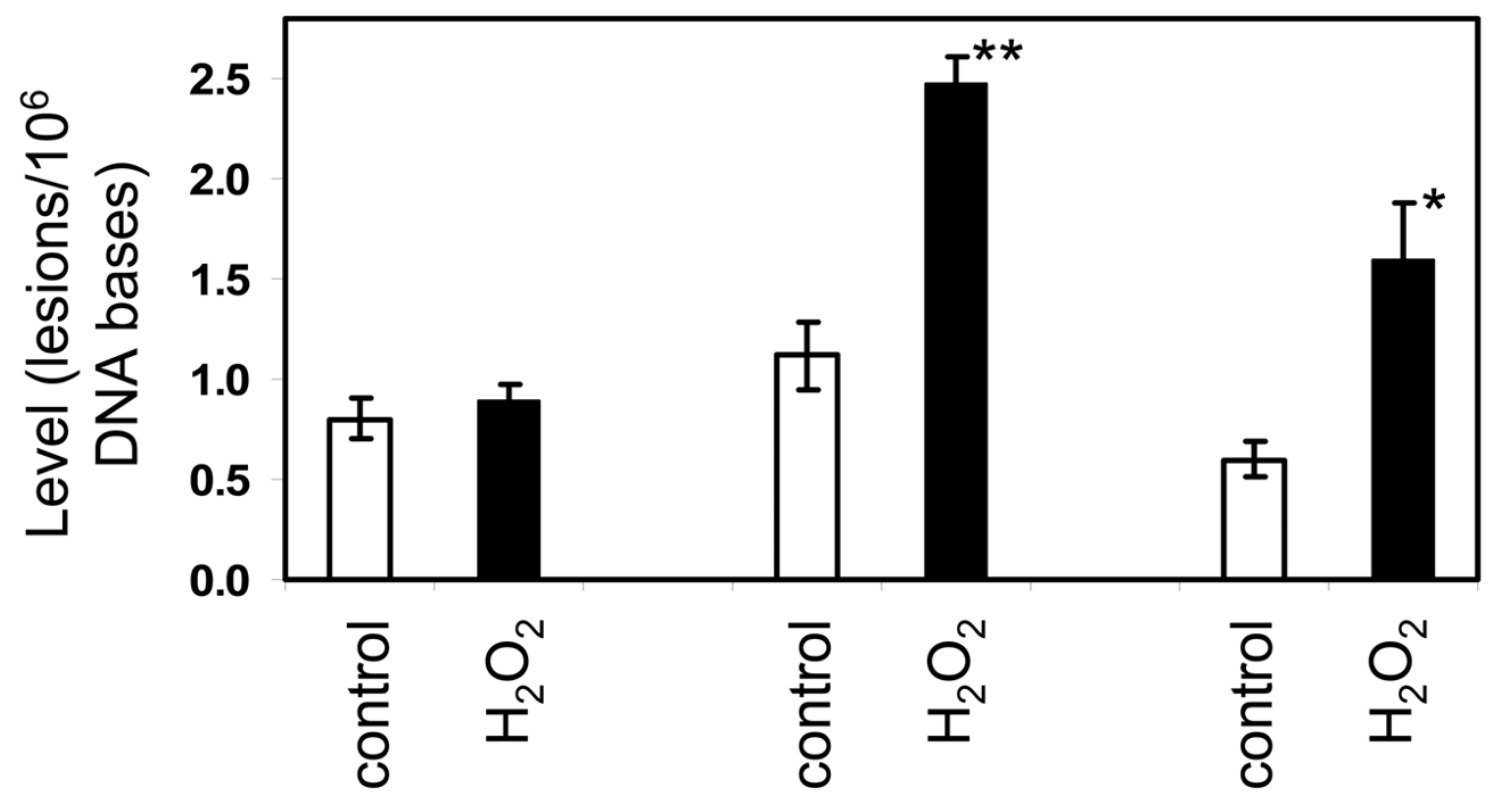

Figure 3

Measurement of 8-OH-dG by LC/MS. Levels of 8-OH-dG in genomic DNA of $\mathrm{H}_{2} \mathrm{O}_{2}$-treated and untreated samples were measured using LC/MS in genomic DNA. Panel $\mathbf{A}$ shows the chemical structure of 8-OH-dG and, panel $\mathbf{B}$ shows the measured levels of 8-OH-dG in untreated (open bars) and treated samples with $300 \mu \mathrm{M}$ of $\mathrm{H}_{2} \mathrm{O}_{2}$ (solid bars). The results are representative of three independent experiments and the error bars represent standard deviation. Statistical analysis (t-test) was performed by comparing the means of the treated with untreated samples. * Represents a statistically significant value of $p<0.02$, and ** represents a statistically significant value of $p<0.005$. 


\section{AG11134 MCF-7 HCC1937}
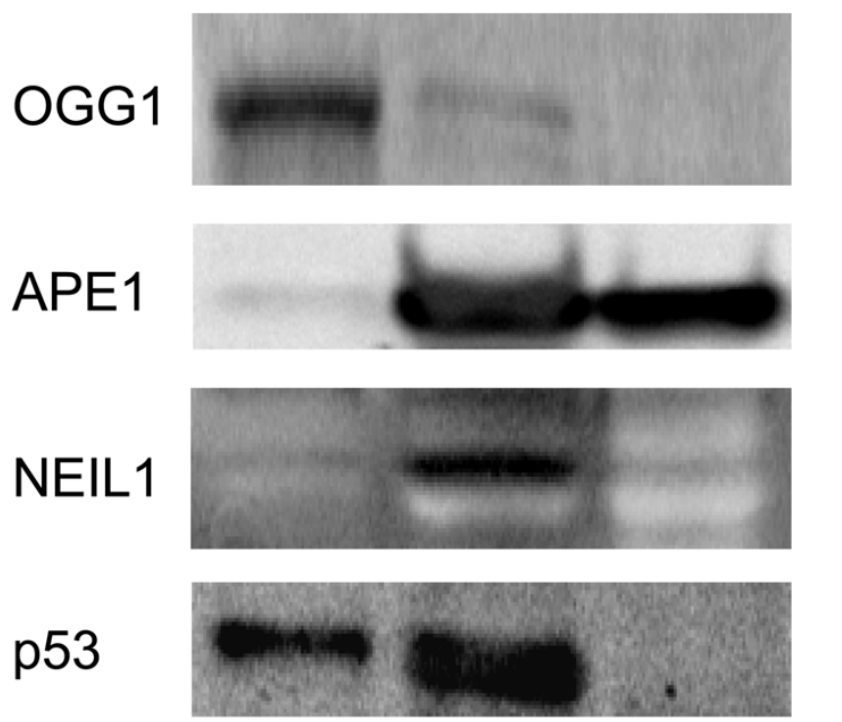

$\beta$-actin

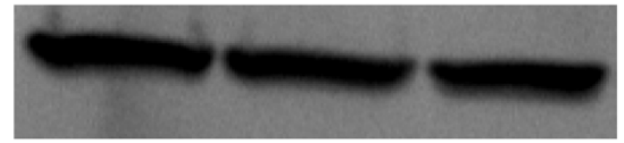

B

\section{AG11134 HCC1937 MCF-7}
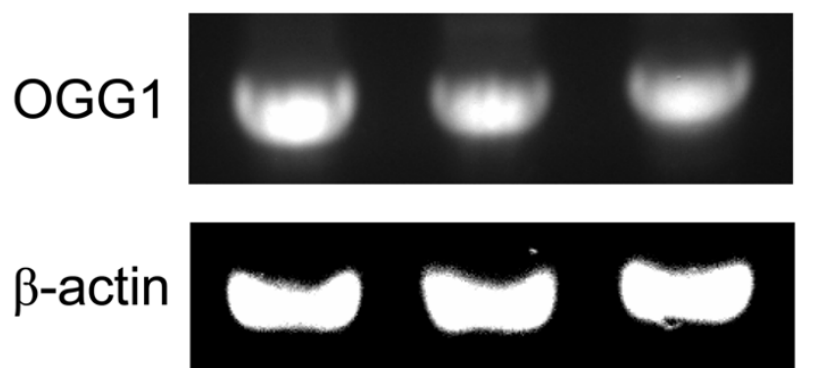

\section{Figure 4}

Expression of specific DNA repair proteins. Total proteins $(50 \mu \mathrm{g})$ were separated by SDS-PAGE and the proteins transferred onto a PVDF membrane. The immunoblots were probed with antibodies against the specific proteins. Panel $\mathbf{A}$ represents basal levels of OGGI, NEILI, p53 and APEI in AGIII 34, MCF-7 and HCCI 937 and, panel B shows RTPCR showing the levels of OGGI la mRNA transcripts in AGIII 34, HCCI 937 and MCF-7 cells. $\beta$-actin was used as a loading control.

both HCC1937 and MCF-7 cells (Fig. 4B). These results were verified by real time PCR (data not shown).

\section{Stimulation of 8-OH-Gua repair in $\mathrm{HCCl} 937$ nuclear extracts by purified hOGGI}

Given that HCC1937 nuclear extracts exhibited diminished nicking activity of 8-OH-Gua and anti-hOGG1 antibodies did not detect hOGG1 in HCC1937, we speculated that addition of purified hOGG1 in HCC1937 extracts would restore the repair of 8-OH-Gua. Addition of purified hOGG1 to HCC1937 nuclear extracts resulted in significant stimulation of 8 -OH-Gua repair in a concentration dependent manner resulting in the expected $\beta$-elimination and weak $\delta$-elimination products (Fig. 5A and 5B). These results further prove that the reduced incision of 8-OH-Gua in HCC1937 cells is indeed related to the lack of hOGG1 in these cells.

\section{Transfection of hOGGI in HCCI 937 enhances 8-OH-Gua repair}

In order to further ascertain that lack of hOGG1 contributed to the reduced in vivo repair of $8-\mathrm{OH}-\mathrm{Gua}$ in HCC1937 cells, we transiently transfected the hOGG1 gene into HCC1937 cells. Western blot analysis revealed that HCC1937 cells transfected with a plasmid carrying the hOGG1 gene expressed detectable levels of hOGG1, while HCC1937 cells transfected with the plasmid alone (without hOGG1 gene) expressed undetectable amounts of hOGG1 (Fig. 6A). Incision assay showed that nuclear extracts prepared from HCC1937 cells expressing hOGG1 exhibited higher 8-OH-Gua-specific incision activity, while nuclear extracts from cells transfected with the vector alone had limited or no excision repair activity (Fig. $6 B)$.

\section{Altered expression of antioxidant enzymes in HCCI 937 cells}

Cells express antioxidant enzymes as a means of extra protection against oxidatively induced DNA damage. We therefore analyzed the level of antioxidant enzymes, SOD1, SOD2 and catalase in HCC1937 and MCF-7 nuclear extracts relative to the control extracts. Interestingly, the level of SOD1 was considerably increased in both breast cancer cell lines, HCC1937 and MCF-7 (Fig. 7). The mitochondrial antioxidant enzyme, SOD2, was over-expressed in HCC1937 cells, whereas catalase was expressed at wild type level in both breast cancer cell lines (Fig. 7).

\section{Reduced clonogenic survival of HCCl 937 cells after oxidative stress}

In order to determine whether the increased level of oxidatively induced DNA damage and upregulation of SOD1 and SOD2 affected cellular survival, we analyzed the clonogenic survival after oxidative stress induction by $\mathrm{H}_{2} \mathrm{O}_{2}$. Our results show that HCC1937 cell line was more sensi- 

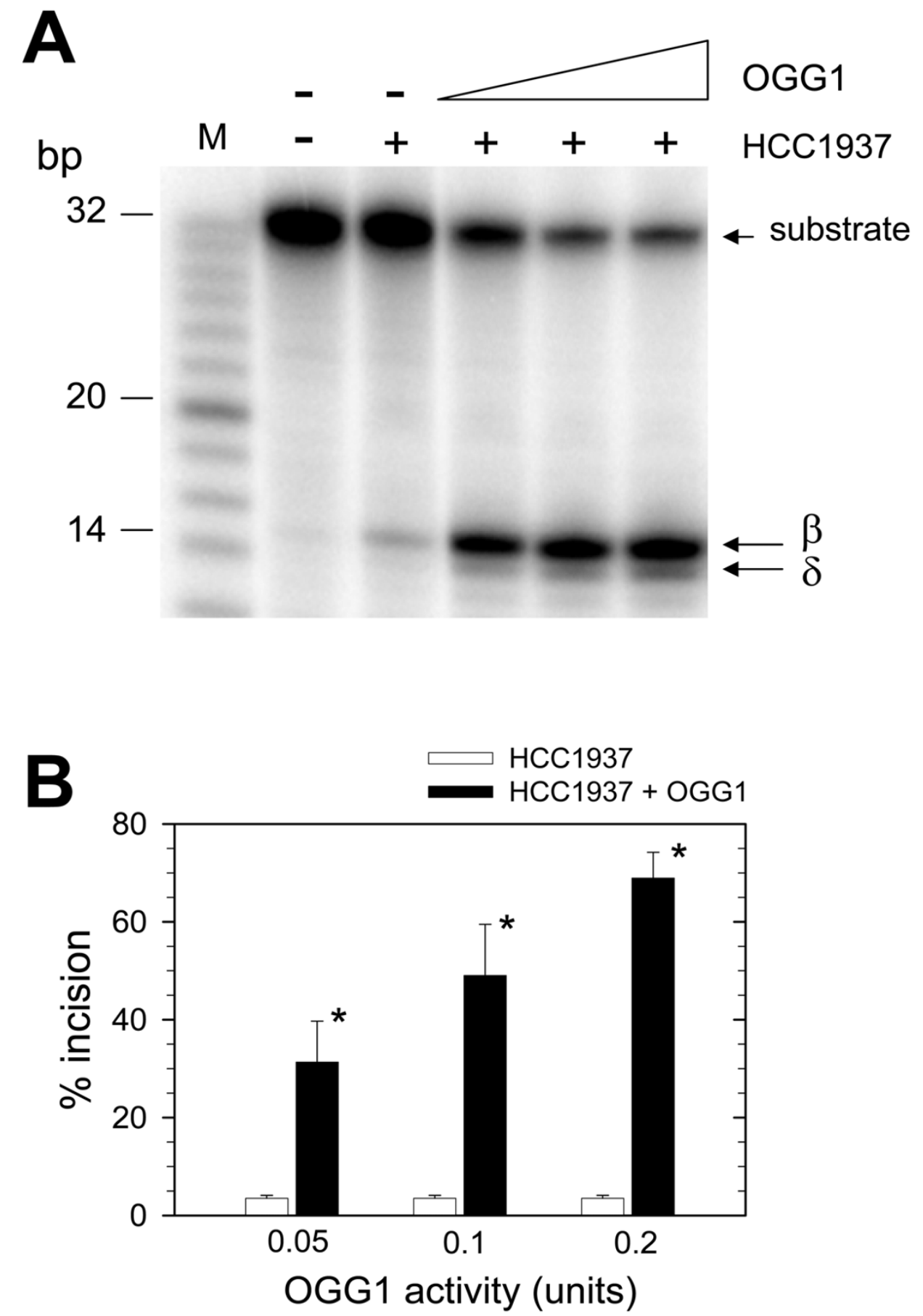

Figure 5

Stimulation of 8-OH-Gua-specific incision activity of HCCI937 nuclear extracts by purified OGG I. HCCI937 nuclear extracts $(50 \mu \mathrm{g})$ were incubated with a 5 ' end-labeled oligonucleotide containing a single $8-\mathrm{OH}-\mathrm{Gua}$ in the presence of increasing amounts of hOGGI for I h. Reactions were stopped and the products separated by electrophoresis through $20 \%$ polyacrylamide gels containing $7 \mathrm{M}$ urea. The band images were analyzed by Phosphorlmager and quantified using ImageQuant software. Panel A, a representative gel image showing the incision reaction products, panel $\mathbf{B}$, quantified results of the incision reaction products. One-way ANOVA revealed a statistically significant difference of $p<0.002(*)$ in the stimulation of activity by purified hOGGI. A unit of hOGGI catalyzes the cleavage of I picomole of a duplex $32 \mathrm{P}$-labeled oligonucleotide in I h at $37^{\circ} \mathrm{C}$ at $8-\mathrm{OH}-\mathrm{Gua} / \mathrm{C}$ base pair. 


\section{A pCMV-4 + OGG1 vector}

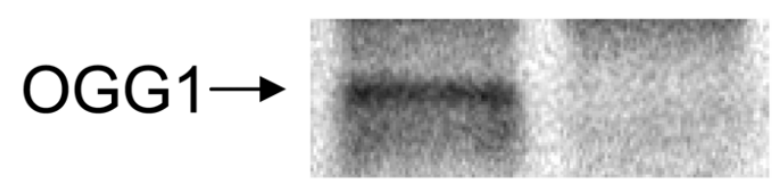

B

\section{pCMV-4}
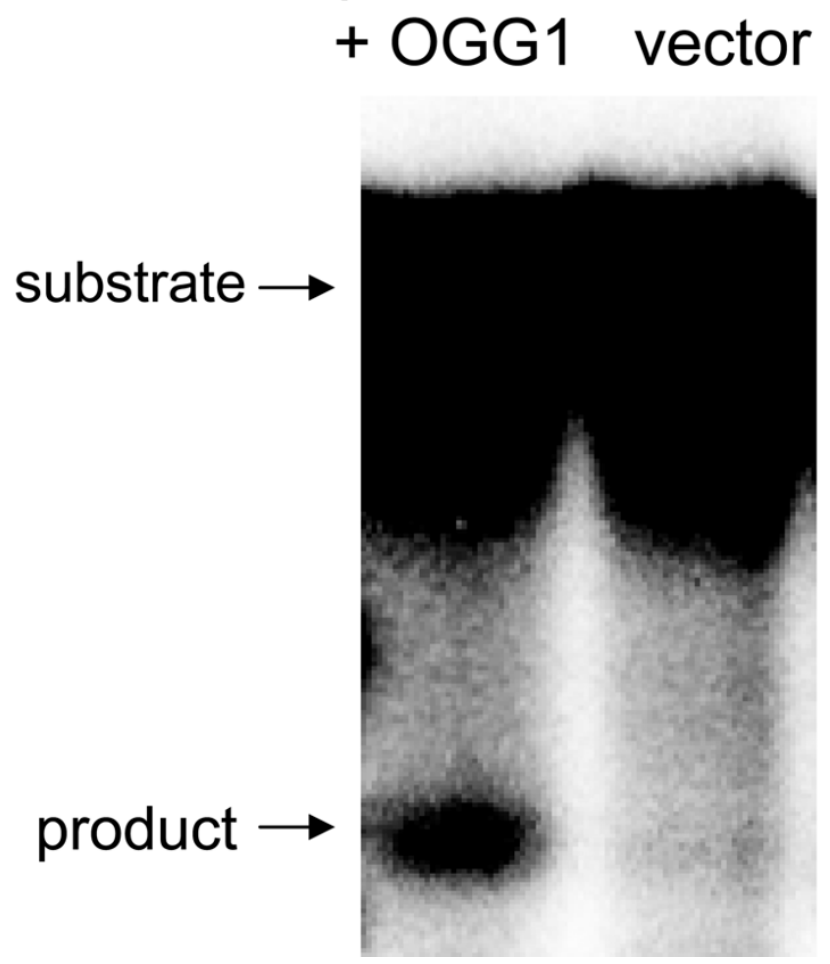

\section{Figure 6}

Incision of 8-OH-Gua by HCCI 937 nuclear extracts after transfection with pFlag-CMV-4-OGGI. HCCI 937 cells $\left(2.5 \times 10^{6}\right)$ were transfected with either pFlag-CMV-4 carrying hOGGI gene or PFlag-CMV-4 without hOGGI gene and nuclear extracts and whole cell extracts were prepared $48 \mathrm{~h}$ after transfection. Western blot analysis was performed using whole cell extracts and incision reactions performed using nuclear extracts and a duplex 5 ' end-labeled oligonucleotide containing a single $8-\mathrm{OH}-\mathrm{Gua}$. Panel $\mathbf{A}$, shows the expression of pFlag-CMV-4-OGGI in HCCI 937 cells and, panel $\mathbf{B}$, shows the incision of $8-\mathrm{OH}-\mathrm{Gua}$ by nuclear extracts containing the transfected pFlag-CMV-4-OGGI or just the vector alone. tive to high concentrations of $\mathrm{H}_{2} \mathrm{O}_{2}$ compared to both AG11134 and MCF-7 cell lines (Fig. 8). Conversely, MCF7 cells were more resistant to $\mathrm{H}_{2} \mathrm{O}_{2}$ than either the HCC1937 or the AG11134 cells. These results suggest that HCC1937 cells and the MCF-7 cells use different mechanisms to survive $\mathrm{H}_{2} \mathrm{O}_{2}$ - mediated stress. These results further suggest that oxidatively induced DNA damage repair and misregulation of antioxidants SOD1 and SOD2 may play a role in influencing the clonogenic survival of cells to $\mathrm{H}_{2} \mathrm{O}_{2}$-induced oxidative stress. Furthermore, these results suggest that the limited survival of HCC1937 cells may be partly due to the up-regulation of SOD1 and SOD2.

\section{Discussion}

We report here that HCC1937 breast cancer cell line is deficient in the in vitro and in vivo repair of 8-OH-Gua, compared to the nonmalignant mammary epithelial cell line, AG11134. An incision assay showed that HCC1937 nuclear extracts had significantly reduced ability to incise a duplex 8-OH-Gua-containing oligonucleotide compared to the control AG11134 nuclear extracts (Fig. 1AD). This deficiency correlated with lack of expression of the hOGG1 in HCC1937 cells (Fig. 4A). Defective repair of 8-OH-Gua is not a unique characteristic of HCC1937 cells since defective repair of this lesion has been reported in other cell types. To this end, our laboratory has previously reported a deficiency in the repair of 8-OH-Gua in mitochondria of the breast cancer cell lines, MCF-7 and MDA-MB-468 [17]. Interestingly, these cell lines exhibited normal nuclear repair of 8-OH-Gua and expressed normal levels of both nuclear and mitochondrial forms of the hOGG1. Furthermore, we recently showed that two prostate cancer cell lines, PC-3 and DU-145 are deficient in the nuclear and mitochondrial repair of 8-OH-Gua [19]. These cell lines expressed normal levels of the nuclear OGG1 but significantly low levels of the mitochondrial OGG1. Colorectal cancer cell lines have also been shown to be defective in the repair of 8-OH-Gua [23]. It has also been shown that Cockayne syndrome cells are deficient in 8-OH-Gua [24-26]. In addition, deficient 8-OH-Gua repair has been reported in lung cancer cell lines with reduced hOGG1 mRNA and protein expression [27]. Reduced 8-OH-Gua repair has recently been reported in isogenic cell lines (HCT116 p53+/+ and HCT116 p53/-) exhibiting reduced hOGG1 mRNA and protein expression after p53 down-regulation and oxidative stress challenge [28]. Furthermore, HCC1937 cell-free extracts are defective in transcription-coupled repair of 8-OH-Gua [18]. The studies discussed above along with the present study indicate that 8-OH-Gua repair is critical in different cell types and implicate hOGG1 levels/activity in certain forms of cancer. The stability of hOGG1 1a mRNA in HCC1937 is not known and may as well be important in the defective repair. On the other hand, HCC1937 cells 


\section{AG11134 HCC1937 MCF-7}

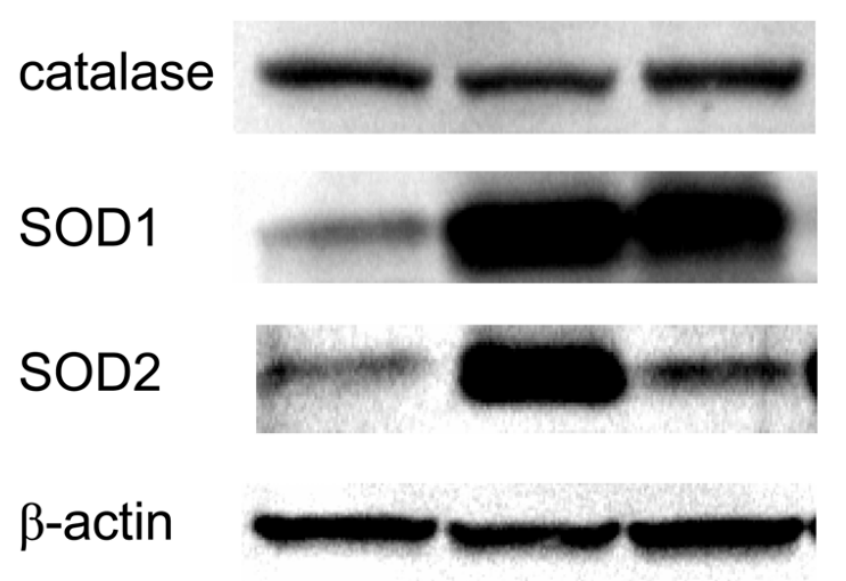

\section{Figure 7}

Expression of antioxidants in HCCI 937 and MCF-7 relative to AG I I I34. Western Blot analysis of SODI, SOD2 and catalase showing their levels in the two breast cancer cell lines compared to the normal mammary epithelial cell line, AG I I 34. $\beta$-actin was used as a loading control. The gels are representatives of three independent analyses in each case.

were proficient in the mitochondrial repair of 8-OH-Gua (data not shown). Interestingly, the mitochondrial repair of 8-OH-Gua was more effective in HCC1937 cells than the normal cell line at higher time points (data not shown), suggesting that OGG1 $2 \mathrm{a}$ is more active than the OGG1 1a in HCC1937 cells.

We noted that MCF-7 nuclear extracts incised 8-OH-Gua at a higher rate than the HCC1937 and AG11134 nuclear extracts, probably due to expression of hOGG1 and better stimulation of OGG1 activity resulting from a higher expression level of APE1 and NEIL1 compared to AG11134 and HCC1937 cells (Fig. 4A). This may be the case since APE1 and NEIL1 have been shown to functionally interact and to stimulate the activity of hOGG1 [2932]. The deficient repair of 8-OH-Gua in HCC1937 cells may not be associated with low APE1 or NEIL1 expression since APE1 expression is up-regulated in HCC1937 cells and NEIL1 is expressed at wild type level in HCC1937 cells (Fig. 4A). This is in agreement with the evidence that hNEIL1 as well as mouse NEIL1 do not remove 8-OH-Gua from DNA [33]. The defective repair is most likely lesionspecific rather than a generalized BER defect since HCC1937 nuclear extracts repaired uracil at levels comparable to AG11134 extracts (Fig. 2 panels A-D). The efficient uracil repair may be attributed to the ubiquitous nature of uracil DNA glycosylase (UDG), the main enzyme involved in the repair of uracil, and also due to

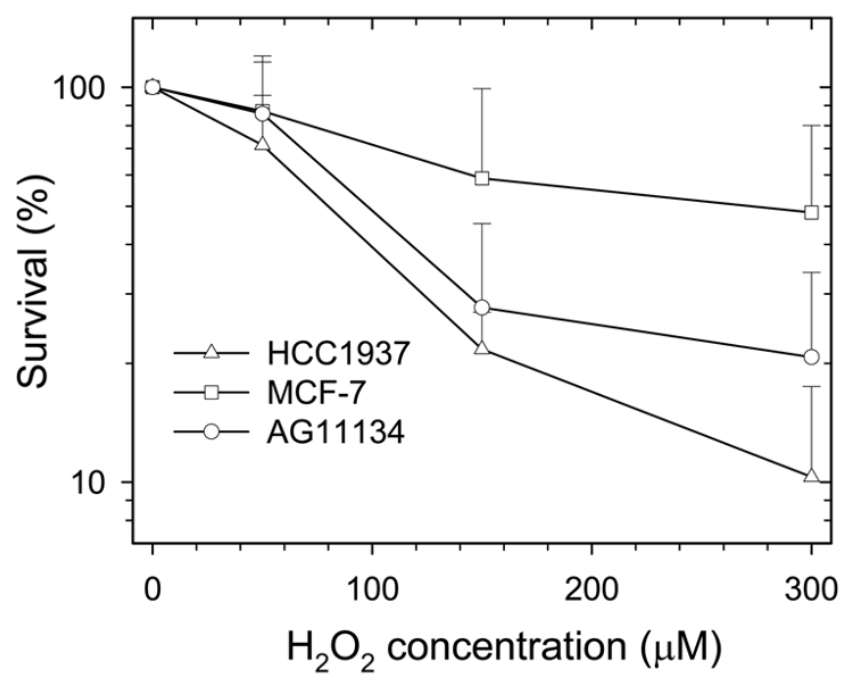

Figure 8

Clonogenic survival to oxidative stress. $1.0 \times 10^{6}$ cells were grown for $24 \mathrm{~h}$ in $37^{\circ} \mathrm{C}$ and $5 \% \mathrm{CO}_{2}$ incubators. Following this incubation, the cells were washed with $1 \times$ PBS and treated with $\mathrm{H}_{2} \mathrm{O}_{2}$ in PBS for 30 min. The cells were washed twice with $1 \times$ PBS and incubated at $37^{\circ} \mathrm{C}, 5 \% \mathrm{CO}_{2}$ in their respective media for $2 \mathrm{~h}$. Serial dilutions of the cells were made in media and the dilutions were plated. The cells were then incubated at $37^{\circ} \mathrm{C}, 5 \% \mathrm{CO}_{2}$ for 20 days. The cells were washed twice with I $\times$ PBS and then stained with $0.02 \%$ crystal violet. The surviving colonies were scored using MCID computer software. The symbols are, diamonds for AG I I 34, squares for MCF-7 and triangles for HCC 937. The experiments were performed in triplicates and the error bars represent standard error of mean.

the redundancy of uracil excision repair [34]. The incision of uracil provided another control for extract activity.

The breast cancer cell lines, HCC1937 and MCF-7 accumulated statistically significant levels of 8 -OH-Gua (measured by LC/MS as its nucleoside $8-\mathrm{OH}-\mathrm{dG}$ ) after induction of oxidative stress by treatment with $\mathrm{H}_{2} \mathrm{O}_{2}$ despite allowing the cells time to repair the DNA damage (Fig. 3B). This accumulation of 8-OH-Gua may be a consequence of inefficient in vivo repair of 8-OH-Gua in the case of HCC1937 cells. This implies that HCC1937 cells may be sustaining an overwhelming level of ROS-induced DNA damage endogenously, a situation that could be exacerbated by exogenous oxidative stress challenge by treatment with $\mathrm{H}_{2} \mathrm{O}_{2}$ and the lack of hOGG1. Consistent with our findings there is evidence that inactivation of $\mathrm{Fpg}$, MutT and Ogg1 resulted in increased levels of 8-OHGua that correlated with expression of mutator phenotypes in E. coli and yeast $[3,35]$. Ogg1 knockout mice exhibit increased levels of 8-OH-Gua in their livers [3638]; however, these animals have only a modest increase in mutation frequency, probably due to DNA repair path- 
way redundancies. The LC/MS data indicate that the MCF7 cell line is defective in the repair of 8-OHGua (Fig. 3B); however, the incision assay shows that this cell line repairs 8-OH-Gua effectively (Fig. 1C and 1D). These varied observations are not surprising since the LC/MS data are reflective of the more in vivo situation, whereas the incision assay is semi-in vivo that utilizes an oligonucleotide with only one lesion at a defined position. On the contrary, the LC/MS data are reflective of multiple 8-OH-Gua lesions that are introduced in the genomic DNA by $\mathrm{H}_{2} \mathrm{O}_{2}$ treatment of the cells. Our 8-OH-Gua measurements in the breast cancer cells are consistent with those reported for frozen breast tissues of women with breast cancer compared with normal breast tissue of women undergoing reduction mamoplasty [39].

The correlation between reduced repair of 8-OH-Gua and lack of OGG1 in HCC1937 cells would imply that adding the purified enzyme or enhancing its expression by transfection of the hOGG1 gene, would result in stimulation of the repair activity. The ability of purified hOGG1 to stimulate the 8-OH-Gua-incision activity of HCC1937 extracts (Fig. 5A and 6B) indicates that hOGG1 is required for efficient repair of 8-OH-Gua in these cells. The in vivo transient expression of a plasmid carrying hOGG1 gene in HCC1937 cells (Fig. 6A) resulted in 8-OH-Gua incision activity greater than the activity in extracts prepared from HCC1937 cells transfected with the vector alone (Fig. 6B). This in vitro and in vivo stimulation of 8-OH-Gua-repair by either the purified hOGG1 or the expressed hOGG1 after transfection of the hOGG1 gene directly implicates hOGG1 in the defective repair of 8-OH-Gua and suggests that the cellular levels of hOGG1 may be related to the functional activity of this enzyme in HCC1937 cells. These results are consistent with a number of studies that have clearly shown that defective mitochondrial repair in HeLa cells and pulmonary artery endothelial cells could be enhanced significantly by transfection with a plasmid carrying mitochondrial hOGG1 gene $[40,41]$.

Altered enzymatic activity of the hOGG1 can result from mutations in the corresponding gene. This is supported by a report showing that a guanine to adenine mutation in the hOGG1 gene changes Arg46 to Gln46, and this amino acid change results in production of a hOGG1 with reduced activity [42]. Furthermore, the polymorphic hOGG1 (S326C) has reduced incision activity of 8-OHGua and is associated with cancer in certain human populations $[9,43]$. Our data on the sequence analysis of all the exons and the promoter region of the hOGG1 gene in HCC1937 cells did not reveal any mutations (data not shown), suggesting that the repair defect was not due to a genetic change.
The survival of cells to genotoxic stress is influenced by a number of factors including antioxidant enzymes. The upregulation of antioxidants SOD1 and SOD2 that we observed in HCC1937 cells (Fig. 7) may be an indication of increased oxidatively induced stress in these cells. The increased stress may in turn trigger a mechanistic response involving up-regulation of SOD1 and SOD2 that in turn reduces the toxicity of superoxide anion thereby confering some cellular survival. The high level of SOD2 in the mitochondrial extracts of HCC1937 cells is consistent with high metabolic activity in this organelle and may occur in response to accumulation of high levels of ROS and increased DNA damage in the mitochondrial genome [44].

The absence of hOGG1 in HCC1937 cells implies that these cells may be highly susceptible to oxidatively induced DNA damage. Indeed, we observed that HCC1937 cells were more sensitive to $\mathrm{H}_{2} \mathrm{O}_{2}$ treatment compared to MCF-7 and AG11134 cells at high $\mathrm{H}_{2} \mathrm{O}_{2}$ levels (Fig. 8). This sensitivity correlates with the lack of hOGG1 (Fig. 4A) and is probably exacerbated by increased oxidatively induced DNA damage (Fig. 3B) in this cell line. The reduced clonogenic survival of HCC1937 cells after $\mathrm{H}_{2} \mathrm{O}_{2}$ challenge relative to MCF-7 and AG11134 cells (Fig. 8) is consistent with the previously reported high degree of sensitivity of these cells to $\mathrm{H}_{2} \mathrm{O}_{2}$ treatment in the presence of DNA repair inhibitors [45]. Furthermore, HCC1937 cells were shown to be hypersensitive to ionizing radiation, a phenomenon that was reversed by expression of non-growth suppressing forms of BRCA1 [18]. In addition, single cell gel electrophoresis (comet) assay revealed that HCC1937 cells accumulate high levels of SSB and DSB relative to the control cells after exposure to 10 Gy of ionizing radiation followed by a repair period (data not shown). MCF-7 cells appear to be more resistant to oxidative stress than HCC1937 cells probably due to their effectiveness in incising 8-OH-Gua (Fig. 1C and 1D).

A monoclonal antibody against p53 did not detect any appreciable $\mathrm{p} 53$ protein in HCC1937 cells while this protein was over-expressed in MCF-7 cells relative to the control AG11134 (Fig. 4A). The lack of detectable p53 in HCC1937 cells may suggest a role for this protein in the repair of 8-OH-Gua in HCC1937 cells. Recently, Achanta and Huang used p53 isogenic cell lines HCT116 p53+/+ and HCT116 p53\% to show that the former cell line excised 8-OH-Gua more rapidly than the latter [46]. Chatterjee et al., recently confirmed these findings using the same isogenic cell lines by showing that HCT116 p53\% exhibited significant reduction in OGG1 activity [28]. This same group further showed that down-regulation of p53 resulted in decreased expression of OGG1 mRNA/ protein after oxidative DNA damage induction and that 
these events correlated with reduced incision of $8-\mathrm{OH}-$ Gua. Taken together these studies suggest that the defective repair of 8-OH-Gua in HCC1937 cells may be associated with complex protein interactions involving OGG1 and other proteins.

The likelihood of BRCA1 playing a role in the repair of 8$\mathrm{OH}-\mathrm{Gua}$ in HCC1937 cells cannot be ruled out especially since HCC1937 cell line harbors a C-terminally truncated BRCA1 due to a $5382 \mathrm{C}$ insertion mutation on the BRCA1 gene [47]. In contrast, the MCF-7 cell line carries a wild type BRCA1 and our studies showed that it incised the 8$\mathrm{OH}$-Gua-containing oligonucleotide quite effectively (Fig. 1 panel $\mathrm{C}$, and panel $\mathrm{D}$, open squares). A possible role for BRCA1 in oxidative DNA damage repair could be achieved through direct interactions with proteins that repair DNA damage. Alternatively, such a role can occur indirectly through interactions with proteins that regulate the stability or expression of the DNA repair proteins. It is noteworthy that the deleted carboxyl terminal domain of BRCA1 in HCC1937 contains the BRCT domain that is thought to mediate BRCA1 interactions with other DNA interactive proteins [48] and is also found in many other proteins involved in DNA repair and DNA damage cell cycle check point control [49-51]. Furthermore, mutant murine Brca1 and mutant human BRCA1 cells are hypersensitive to oxidative DNA damaging agents such as ionizing radiation and hydrogen peroxide [18,52].

Thus, we have shown that HCC1937 breast cancer cell line is deficient in the incision of 8-OH-Gua and accumulates significantly high levels of this lesion after $\mathrm{H}_{2} \mathrm{O}_{2}$ treatment followed by a repair period. This cell line does not express any detectable level of hOGG1, linking this enzyme to the inefficient 8-OH-Gua-repair. The DNA repair deficiency was stimulated in vitro by addition of purified hOGG1. Furthermore, the transfection of a plasmid carrying the hOGG1 1a gene and in vivo expression of hOGG1 in HCC1937 cells resulted in increased incision of 8-OH-Gua. HCC1937 cells were more sensitive to high $\mathrm{H}_{2} \mathrm{O}_{2}$ concentrations compared to both AG11134 and MCF-7 cells. This work implicates hOGG1 in the defective repair of 8-OH-Gua in HCC1937 cells and suggests that oxidatively induced DNA damage is a critical factor in breast cancer.

\section{Conclusion}

This research has shown that HCC1937 breast cancer cells are deficient in the repair of 8-OH-Gua. The increased expression of hOGG1 and enhanced incision of 8-OHGua in HCC1937 cells after transfection with a plasmid carrying the hOGG1 directly implicates hOGG1 in the defective repair of 8-OH-Gua. This defect is underscored by the accumulation of statistically significant levels of 8 $\mathrm{OH}$-dG in the breast cancer cells after $\mathrm{H}_{2} \mathrm{O}_{2}$-mediated oxi- dative stress relative to the nonmalignant mammary cell line despite a DNA repair period. Taken together, these findings implicate defective 8-OH-Gua repair in certain breast cancer cell lines and suggest that oxidative DNA damage could be a risk factor in the development/progression of a proportion of breast cancers.

\section{Abbreviations}

BER, base excision repair; ROS, reactive oxygen species; LC/MS, liquid chromatography/mass spectrometry; GC/ MS, gas chromatography/mass spectrometry; 8-OH-Gua, 8-hydroxyguanine; 8-OH-dG, 8-hydroxy-2'-deoxyguanosine; TCR, transcription-coupled repair; SSB, single-strand breaks; DSB, double-strand breaks.

\section{Competing interests}

The author(s) declare that they have no competing interests.

\section{Authors' contributions}

SGN co-designed the study with MKE, wrote the manuscript, prepared extracts, performed incision assays, treated and isolated genomic DNA for 8-OH-dGua measurements, performed transfection and DNA repair complementation studies, RT-PCR and clonogenic survival assays. AL performed cell culture work, Western blot analysis and participated in incision studies, RT-PCR and clonogenic survival studies. PJ and MD measured the 8-OHdG levels by LC/MS and contributed in part to the preparation of the manuscript. ART performed the statistical analysis and assisted in figure preparation. MKE cOdesigned the study with SGN, coordinated, supervised the study and edited the manuscript. All the authors read and approved the final manuscript.

\section{Acknowledgements}

We are grateful to Drs. Sankar Mitra and Tapas Hazra (University of Texas Medical Branch, Galveston, Texas) for their generous gifts of hOGGI-containing plasmid and purified NEILI. Dr. Dan Longo is thanked for useful suggestions and Drs. Myriam Gorospe and Patrice J. Morin are thanked for critically reading the manuscript. Janice Barnes is thanked for technical help. This research was supported by the Intramural Research Program of the $\mathrm{NIH}$, National Institute on Aging. Certain commercial equipment or materials are identified in this paper in order to specify adequately the experimental procedure. Such identification does not imply recommendation or endorsement by the National Institute of Standards and Technology, nor does it imply that the materials or equipment identified are necessarily the best available for the purpose.

\section{References}

I. Dizdaroglu M, Rao G, Halliwell B, Gajewski E: Damage to the DNA bases in mammalian chromatin by hydrogen peroxide in the presence of ferric and cupric ions. Arch Biochem Biophys 1991, 285(2):317-324.

2. Grollman AP, Moriya M: Mutagenesis by 8-oxoguanine: an enemy within. Trends Genet 1993, 9(7):246-249.

3. Tajiri T, Maki H, Sekiguchi M: Functional cooperation of MutT, MutM and MutY proteins in preventing mutations caused by 
spontaneous oxidation of guanine nucleotide in Escherichia coli. Mutat Res 1995, 336(3):257-267.

4. Hazra TK, Hill JW, Izumi T, Mitra S: Multiple DNA glycosylases for repair of 8-oxoguanine and their potential in vivo functions. Prog Nucleic Acid Res Mol Biol 200I, 68:193-205.

5. Michaels ML, Miller JH: The GO system protects organisms from the mutagenic effect of the spontaneous lesion 8hydroxyguanine (7,8-dihydro-8-oxoguanine). J Bacteriol 1992, I 74(20):632I-6325.

6. Radicella JP, Dherin C, Desmaze C, Fox MS, Boiteux S: Cloning and characterization of hOGGI, a human homolog of the OGG I gene of Saccharomyces cerevisiae. Proc Natl Acad Sci U S A 1997 , 94(15):8010-8015.

7. Nash HM, Bruner SD, Scharer OD, Kawate T, Addona TA, Spooner $\mathrm{E}$, Lane WS, Verdine GL: Cloning of a yeast 8-oxoguanine DNA glycosylase reveals the existence of a base-excision DNArepair protein superfamily. Curr Biol 1996, 6(8):968-980.

8. Rosenquist TA, Zharkov DO, Grollman AP: Cloning and characterization of a mammalian 8-oxoguanine DNA glycosylase. Proc Natl Acad Sci U S A 1997, 94( I 4):7429-7434.

9. Dherin C, Radicella JP, Dizdaroglu M, Boiteux S: Excision of oxidatively damaged DNA bases by the human alpha-hOggI protein and the polymorphic alpha-hOggl(Ser326Cys) protein which is frequently found in human populations. Nucleic Acids Res 1999, 27(20):400I-4007.

10. Slupphaug G, Kavli B, Krokan HE: The interacting pathways for prevention and repair of oxidative DNA damage. Mutat Res 2003, 53 I (I-2):23I-25I.

II. Dianov G, Bischoff C, Piotrowski J, Bohr VA: Repair pathways for processing of 8-oxoguanine in DNA by mammalian cell extracts. J Biol Chem I998, 273(50):338II-33816.

12. Cooke MS, Evans MD, Dizdaroglu M, Lunec J: Oxidative DNA damage: mechanisms, mutation, and disease. Faseb J 2003, I7(10): I195-1214.

13. Malins DC, Haimanot R: Major alterations in the nucleotide structure of DNA in cancer of the female breast. Cancer Res | 991, 5 I (19):5430-5432.

14. Malins DC, Holmes EH, Polissar NL, Gunselman SJ: The etiology of breast cancer. Characteristic alteration in hydroxyl radicalinduced DNA base lesions during oncogenesis with potential for evaluating incidence risk. Cancer 1993, 7 I(10):3036-3043.

15. Olinski R, Zastawny T, Budzbon J, Skokowski J, Zegarski W, Dizdaroglu M: DNA base modifications in chromatin of human cancerous tissues. FEBS Lett 1992, 309(2): 193-198.

16. Parshad R, Price FM, Bohr VA, Cowans KH, Zujewski JA, Sanford KK: Deficient DNA repair capacity, a predisposing factor in breast cancer. Br J Cancer 1996, 74(I): I-5.

17. Mambo E, Nyaga SG, Bohr VA, Evans MK: Defective repair of 8hydroxyguanine in mitochondria of MCF-7 and MDA-MB468 human breast cancer cell lines. Cancer Res 2002, 62(5): $1349-1355$

18. Abbott DW, Thompson ME, Robinson-Benion C, Tomlinson G, Jensen RA, Holt JT: BRCAI expression restores radiation resistance in BRCAI-defective cancer cells through enhancement of transcription-coupled DNA repair. J Biol Chem 1999, 274(26): $18808-18812$

19. Trzeciak AR, Nyaga SG, Jaruga P, Lohani A, Dizdaroglu M, Evans MK: Cellular repair of oxidatively induced DNA base lesions is defective in prostate cancer cell lines, PC-3 and DU- I45. Carcinogenesis 2004, 25(8): 1359-1370.

20. Nyaga SG, Bohr VA: Characterization of specialized mtDNA glycosylases. Methods Mol Biol 2002, 197:227-244.

21. Miller SA, Dykes DD, Polesky HF: A simple salting out procedure for extracting DNA from human nucleated cells. Nucleic Acids Res 1988, 16(3):1215.

22. Jaruga P, Theruvathu J, Dizdaroglu M, Brooks PJ: Complete release of (5'S)-8,5'-cyclo-2'-deoxyadenosine from dinucleotides, oligodeoxynucleotides and DNA, and direct comparison of its levels in cellular DNA with other oxidatively induced DNA lesions. Nucleic Acids Res 2004, 32(I I):e87.

23. Parker AR, O'Meally RN, Oliver DH, Hua L, Nelson WG, DeWeese $T L$, Eshleman JR: 8-Hydroxyguanosine repair is defective in some microsatellite stable colorectal cancer cells. Cancer Res 2002, 62(24):7230-7233.
24. Dianov G, Bischoff C, Sunesen M, Bohr VA: Repair of 8-oxoguanine in DNA is deficient in Cockayne syndrome group $B$ cells. Nucleic Acids Res 1999, 27(5):1365-1368.

25. Selzer RR, Nyaga S, Tuo J, May A, Muftuoglu M, Christiansen M, Citterio $E$, Brosh RM Jr., Bohr VA: Differential requirement for the ATPase domain of the Cockayne syndrome group $B$ gene in the processing of UV-induced DNA damage and 8-oxoguanine lesions in human cells. Nucleic Acids Res 2002, 30(3):782-793.

26. Tuo J, Jaruga P, Rodriguez H, Bohr VA, Dizdaroglu M: Primary fibroblasts of Cockayne syndrome patients are defective in cellular repair of 8-hydroxyguanine and 8-hydroxyadenine resulting from oxidative stress. Faseb J 2003, I7(6):668-674.

27. Mambo E, Chatterjee A, de Souza-Pinto NC, Mayard S, Hogue BA, Hoque MO, Dizdaroglu M, Bohr VA, Sidransky D: Oxidized guanine lesions and hOgg I activity in lung cancer. Oncogene 2005, 24(28):4496-4508.

28. Chatterjee A, Mambo E, Osada M, Upadhyay S, Sidransky D: The effect of p53-RNAi and p53 knockout on human 8-oxoguanine DNA glycosylase (hOggI) activity. Faseb J 2006, 20(I): II2-114

29. Hill JW, Hazra TK, Izumi T, Mitra S: Stimulation of human 8-oxoguanine-DNA glycosylase by AP-endonuclease: potential coordination of the initial steps in base excision repair. Nucleic Acids Res 200 I, 29(2):430-438.

30. Vidal AE, Hickson ID, Boiteux S, Radicella JP: Mechanism of stimulation of the DNA glycosylase activity of hOGGI by the major human AP endonuclease: bypass of the AP lyase activity step. Nucleic Acids Res 200 I, 29(6): I 285- 1292.

31. Saitoh T, Shinmura K, Yamaguchi S, Tani M, Seki S, Murakami H, Nojima Y, Yokota J: Enhancement of OGGI protein AP lyase activity by increase of APEX protein. Mutat Res 200I, 486(I):3I-40

32. Mokkapati SK, Wiederhold L, Hazra TK, Mitra S: Stimulation of DNA glycosylase activity of OGG I by NEILI: functional collaboration between two human DNA glycosylases. Biochemistry 2004, 43(36): I I596-I I604.

33. Jaruga P, Birincioglu M, Rosenquist TA, Dizdaroglu M: Mouse NEILI protein is specific for excision of 2,6-diamino-4-hydroxy-5formamidopyrimidine and 4,6-diamino-5-formamidopyrimidine from oxidatively damaged DNA. Biochemistry 2004, 43(50): $15909-159 \mid 4$

34. Krokan HE, Drablos F, Slupphaug G: Uracil in DNA--occurrence, consequences and repair. Oncogene 2002, 21 (58):8935-8948.

35. Thomas D, Scot AD, Barbey R, Padula M, Boiteux S: Inactivation of OGG I increases the incidence of G . C-->T . A transversions in Saccharomyces cerevisiae: evidence for endogenous oxidative damage to DNA in eukaryotic cells. Mol Gen Genet 1997, 254(2): $171-178$.

36. Klungland A, Rosewell I, Hollenbach S, Larsen E, Daly G, Epe B, Seeberg $E$, Lindahl T, Barnes DE: Accumulation of premutagenic DNA lesions in mice defective in removal of oxidative base damage. Proc Natl Acad Sci U S A 1999, 96(23): 13300-13305.

37. Osterod M, Hollenbach S, Hengstler JG, Barnes DE, Lindahl T, Epe B: Age-related and tissue-specific accumulation of oxidative DNA base damage in 7,8-dihydro-8-oxoguanine-DNA glycosylase (OggI) deficient mice. Carcinogenesis 200I, 22(9): 1459-1463.

38. Minowa $O$, Arai T, Hirano M, Monden $Y$, Nakai S, Fukuda M, Itoh M, Takano H, Hippou Y, Aburatani H, Masumura K, Nohmi T, Nishimura $\mathrm{S}$, Noda T: Mmh/Ogg I gene inactivation results in accumulation of 8-hydroxyguanine in mice. Proc Natl Acad Sci U S A 2000, 97(8):4|56-4|6|.

39. Li D, Zhang W, Zhu J, Chang P, Sahin A, Singletary E, Bondy M, Hazra T, Mitra S, Lau SS, Shen J, DiGiovanni J: Oxidative DNA damage and 8-hydroxy-2-deoxyguanosine DNA glycosylase/apurinic lyase in human breast cancer. Mol Carcinog 200I, 3I(4):2। 4-223.

40. Dobson AW, Grishko V, LeDoux SP, Kelley MR, Wilson GL, Gillespie MN: Enhanced mtDNA repair capacity protects pulmonary artery endothelial cells from oxidant-mediated death. $\mathrm{Am} J$ Physiol Lung Cell Mol Physiol 2002, 283(I):L205-IO.

4I. Rachek LI, Grishko VI, Musiyenko SI, Kelley MR, LeDoux SP, Wilson GL: Conditional targeting of the DNA repair enzyme hOGG I into mitochondria. J Biol Chem 2002, 277(47):44932-44937.

42. Audebert M, Radicella JP, Dizdaroglu M: Effect of single mutations in the OGGI gene found in human tumors on the substrate 
specificity of the OggI protein. Nucleic Acids Res 2000, 28(I4):2672-2678.

43. Hill JW, Evans MK: Dimerization and opposite base-dependent catalytic impairment of polymorphic S326C OGG I glycosylase. Nucleic Acids Res 2006, 34(5): I620-1632.

44. Richter C, Park JW, Ames BN: Normal oxidative damage to mitochondrial and nuclear DNA is extensive. Proc Natl Acad Sci U S A 1988, 85(17):6465-6467.

45. Starcevic SL, Diotte NM, Zukowski KL, Cameron MJ, Novak RF: Oxidative DNA damage and repair in a cell lineage model of human proliferative breast disease (PBD). Toxicol Sci 2003, 75(I):74-8I.

46. Achanta $G$, Huang P: Role of $\mathrm{p} 53$ in sensing oxidative DNA damage in response to reactive oxygen species-generating agents. Cancer Res 2004, 64( I 7):6233-6239.

47. Tomlinson GE, Chen TT, Stastny VA, Virmani AK, Spillman MA, Tonk V, Blum JL, Schneider NR, Wistuba, Shay JW, Minna JD, Gazdar AF: Characterization of a breast cancer cell line derived from a germ-line BRCAI mutation carrier. Cancer Res 1998, 58(I 5):3237-3242.

48. Koonin EV, Altschul SF, Bork P: BRCAI protein products ... Functional motifs. Nat Genet 1996, I3(3):266-268.

49. Bork P, Hofmann K, Bucher P, Neuwald AF, Altschul SF, Koonin EV: A superfamily of conserved domains in DNA damageresponsive cell cycle checkpoint proteins. Faseb J 1997, I I(I):68-76

50. Callebaut I, Mornon JP: From BRCAI to RAPI: a widespread BRCT module closely associated with DNA repair. FEBS Lett 1997, 400(I):25-30

5I. Rodriguez M, Yu X, Chen J, Songyang Z: Phosphopeptide binding specificities of BRCAI COOH-terminal (BRCT) domains. I Biol Chem 2003, 278(52):529|4-529|8.

52. Shen SX, Weaver Z, Xu X, Li C, Weinstein M, Chen L, Guan XY, Ried $T$, Deng CX: A targeted disruption of the murine Brcal gene causes gamma-irradiation hypersensitivity and genetic instability. Oncogene 1998, I7(24):31|5-3124.

\section{Pre-publication history}

The pre-publication history for this paper can be accessed here:

http://www.biomedcentral.com/1471-2407/6/297/pre pub
Publish with Bio Med Central and every scientist can read your work free of charge

"BioMed Central will be the most significant development for disseminating the results of biomedical research in our lifetime. "

Sir Paul Nurse, Cancer Research UK

Your research papers will be:

- available free of charge to the entire biomedical community

- peer reviewed and published immediately upon acceptance

- cited in PubMed and archived on PubMed Central

- yours - you keep the copyright
BioMedcentral 